Original Research Article

\title{
Ophthalmic manifestations of thyroid disease and the association of serum levels of T3, T4 and TSH with thyroid eye disease
}

\author{
Choudhari P.C. ${ }^{1}$, Usgaonkar U. ${ }^{2}$, Shrivastav D. ${ }^{3}$ \\ ${ }^{1}$ Dr. Priyanka Chandrakant Choudhari, Third year Junior Resident, ${ }^{2}$ Dr. Ugam Usgaonkar, Professor and Head, ${ }^{3}$ Dr. Dipti \\ Shrivastav, Assistant Lecturer, all authors are affiliated with Department of Ophthalmology, GMC, Bambolim, Goa, India.
}

Corresponding Author: Dr. Priyanka Choudhari, Third year Junior Resident, Department of Ophthalmology, GMC, Bambolim, Goa, India. Email: piyachoudhari15091986@gmail.com

\begin{abstract}
:
Aim: To study the ophthalmic manifestations in thyroid disease and the association of serum levels of T3, T4 and TSH with thyroid eye disease. Material and methods: The present study was a prospective case series study. It included 72 patients with thyroid disease with either hypo, hyper or euthyroid status visiting ophthalmology department from March to October 2019, at GMC, Bambolim, Goa. Data was entered on SPSS software and analysed by using one-way ANOVA test to study the proportions of thyroid eye disease signs in various thyroid disease types and to establish their relationship with serum levels of T3, T4 and TSH and the duration of thyroid disease. Result: The most common thyroid eye disease was found to be dry eye (41 patients) followed by upper lid retraction (19 patients) and proptosis (14 patients). Serum level of T3 at the time of study was found to be significantly correlated with the severity and the frequency of upper lid retraction. Serum levels of T4 at the time of diagnosis of hyperthyroid was found to be significantly related with the severity and the frequency of the proptosis. Rest all signs of thyroid eye disease (Chemosis, congestion, dry eye) and intraocular pressure were found to be not associated or related with serum levels of T3, T4 and TSH at the time of examination or at the time of diagnosis. Conclusion: Duration of thyroid disease was not found to be significantly related with the frequency and severity of any of the thyroid eye disease signs which were studied with the $\mathrm{p}$ value being more than 0.05 in each subgroup.
\end{abstract}

Keywords: Thyroid disease, Ophthalmic manifestations, Graves' disease

\section{Introduction}

Thyroid Eye Disease (TED) is a complex orbital inflammatory disease, which can be sight threatening, debilitating and disfiguring [1]. Incidence of TED is $16 / 1,00,000$ females and 2.9/1,00,000 males with overall prevalence of $0.25 \%$ [2]. Incidence of thyroid hence thyroid eye disease is more common in females (4:1) but severity of it is more commonly seen in males [3,4,5]. Most common clinical sign in TED is upper eyelid retraction (90\%) followed by exophthalmos $(60 \%)$ and eye movement restrictions (40\%) [6]. Thyroid eye disease was considered as a part of the triad of Graves' disease which included orbital signs, hyperthyroidism and pretibial myxoedema [7]. Thyroid eye disease is more severe in patients with thyroid dysfunction than in those with euthyroid status [7].

Europeans are 6.4 times more likely to develop thyroid eye disease as compared to the Asians [7]. Thyroid eye disease involves 20 eyelid signs along with conjunctival chemosis, congestion, strabismus, corneal exposure, dry eye,

Manuscript received: $8^{\text {th }}$ December 2019

Reviewed: $\mathbf{1 8}^{\text {th }}$ December 2019

Author Corrected: $24^{\text {th }}$ December 2019

Accepted for Publication: $27^{\text {th }}$ December 2019 proptosis, extra-ocular muscle movement restriction, decrease in vision, optic neuropathy in severe cases. The pathogenesis behind the development of orbitopathy in patients with the thyroid disease is not completely well understood but it seems to be an autoimmune process because the tissues contain proteins which appear similar to thyroid gland to the immune system $[8,9,10]$. Many studies have been carried out to study ophthalmic manifestations of thyroid disease, however there are no studies or literature found on association of serum levels of thyroid hormones with thyroid eye disease and this study attempts to seek if any significant relationship exists between these two.

Aim: To study ophthalmic manifestations in thyroid disease patients and to study the association of serum levels of thyroid hormones T3, T4 and TSH with thyroid eye disease signs.

\section{Material and Methods}

Type of study: Prospective caser series study Duration of study: February 2019 to October 2019 
Sample size: 72 cases with thyroid disease

Ethical permission: IEC approval was obtained to carry out this study

\section{Inclusion criteria}

Patients with thyroid disease or those thyroid eye disease with euthyroid status with thyroid hormone profile at the time of diagnosis and at the time of examination visiting Ophthalmology OPD at GMC, Bambolim, Goa and who gave consent for this study are included.

\section{Exclusion criteria}

Patients without thyroid hormone profile or those who didn't give consent are not included in this study. Patients with thyroid disease and with age less than 10-year-old were excluded from the study

Sampling method: Conventional

The patients included in the study their demographic data was recorded along with the serum levels of T3, T4, TSH at the time of diagnosis and examination. All the patients detailed ocular examination was carried out with the help of torch light, and slit lamp for anterior segment evaluation,

\section{Original Research Article}

direct ophthalmoscopy for posterior segment evaluation, indirect ophthalmoscopy whenever necessary. Proptosis was measured with the help of Hurtles exophthalmometer and graded as mild-moderate (less than $3 \mathrm{~mm}$ ) and severe (more than $3 \mathrm{~mm}$ ). Simple ruler scale was used for evaluation of upper lid retraction and it was graded as mildmoderate (less than $2 \mathrm{~mm}$ ) and severe (more than $2 \mathrm{~mm}$ ). Schirmers test was used for the evaluation of dry eye disease and was considered negative if more than $10 \mathrm{~mm}$ of wetness of the Schirmers strip over 5 minutes.

The present study also observed the presence of conjunctival chemosis, congestion, diplopia, restriction to extra ocular movements and intraocular pressure was measured by using Goldman's applanation tonometry technique.

Data analysis: Then data was entered on SPSS software and analysed by using chi square test and one way annova test was used to establish the significance of serum levels of T3, T4, TSH at the time of study and Pre T3, Pre T4 and Pre $\mathrm{TSH}$ at the time of diagnosis of thyroid disease with the severity and the frequency of thyroid eye disease signs.

\section{Results}

Out of 72 cases which were studied, 36 patients were found to be of hypothyroid status, 34 patients were having hyperthyroidism and 2 patients had euthyroid status, out of the 72 patients, females were seen to be more commonly affected than men (Table 1).

Table 1: Distribution of thyroid and gender in the present study population.

\begin{tabular}{|c|c|}
\hline Type of Thyroid & Number of Cases \\
\hline Hypothyroid & $36(50 \%)$ \\
\hline Hyperthyroidism & $34(47.44 \%)$ \\
\hline Euthyroid & $2(2.78 \%)$ \\
\hline Gender & Number of Cases \\
\hline Males & $25(18 \%)$ \\
\hline Females & $54(75 \%)$ \\
\hline
\end{tabular}

Most common age group affected with thyroid disease was 41-50 years (Table 2)

Table-2: Age range.

\begin{tabular}{|c|c|c|c|c|c|}
\hline \multicolumn{2}{|c|}{ In years } & Frequency & Percent & Valid Percent & Cumulative Percent \\
\hline \multirow{6}{*}{} & $10-20$ & 7 & 9.7 & 9.7 & 9.7 \\
\cline { 2 - 6 } & $21-30$ & 2 & 2.8 & 2.8 & 12.5 \\
\cline { 2 - 6 } & $31-40$ & 22 & 30.6 & 30.6 & 43.1 \\
\cline { 2 - 6 } & $41-50$ & 25 & 34.7 & 34.7 & 77.8 \\
\cline { 2 - 6 } & $51-60$ & 11 & 15.3 & 15.3 & 93.1 \\
\cline { 2 - 6 } & $61-70$ & 4 & 5.6 & 5.6 & 98.6 \\
\cline { 2 - 6 } & $81-90$ & 1 & 1.4 & 1.4 & 100.0 \\
\cline { 2 - 6 } & Total & 72 & 100.0 & 100.0 & \\
\hline
\end{tabular}




\section{Original Research Article}

Upper lid retraction was seen in 19 patients out of which 14 patients belonged to hyperthyroid group, 4 patients had hypothyroid status and 1 patient had euthyroid status. One way Annova test was applied to see whether the upper lid retraction was associated with serum levels of thyroid hormones or not, and it was found that only serum levels of T3 at the time of present examination was related with upper lid retraction and its severity with a $\mathrm{p}$ value of 0.009 . Higher the level more the severity of upper lid retraction was seen. Rest thyroid hormone levels didn't show any significant relationship with the frequency and severity of the upper lid retraction with p value more than 0.05 (Table 3).

Table 3 showed significance values after comparing serum levels of T3, T4, TSH levels at the time of examination with upper lid retraction. It showed only serum level of $\mathrm{T} 3$ at the time of examination of this study is related to upper lid retraction significantly with the $\mathrm{p}$ value of 0.009 . Table 3 also represented the relationship between serum levels of T3, T4, TSH and the upper lid retraction in case of hypothyroid cases. This table represented the significance values above 0.05 for each type of serum level of thyroid hormones in case of hypothyroidism, showing there is no significant relationship between these two variables. Table 3 also depicted the relationship between serum levels of T3, T4 and TSH values at the time of diagnosis of the disease in case of hyperthyroidism and the upper lid retraction. In all cases $\mathrm{p}$ value is more than 0.05 so, it can be concluded that these hormone levels don't affect upper lid retraction.

Table 3: Comparison of serum levels of T3, T4 and TSH levels at the time of examination with upper lid retraction along with cases of hypothyroid and hyperthyroidism.

\begin{tabular}{|c|c|c|c|c|c|c|}
\hline & & Sum of Squares & df & Mean Square & $\mathbf{F}$ & Sig. \\
\hline \multirow[t]{3}{*}{ T3 } & Between Groups & 57.233 & 5 & 11.447 & 3.908 & .009 \\
\hline & Within Groups & 79.086 & 27 & 2.929 & & \\
\hline & Total & 136.319 & 32 & & & \\
\hline \multirow[t]{3}{*}{$\mathrm{T} 4$} & Between Groups & 354.414 & 5 & 70.883 & 2.427 & .061 \\
\hline & Within Groups & 788.470 & 27 & 29.203 & & \\
\hline & Total & 1142.884 & 32 & & & \\
\hline \multirow[t]{3}{*}{ TSH } & Between Groups & 107.544 & 5 & 21.509 & .539 & .745 \\
\hline & Within Groups & 1077.259 & 27 & 39.898 & & \\
\hline & Total & 1184.803 & 32 & & & \\
\hline & & Sum of Squares & df & Mean Square & $\mathbf{F}$ & Sig. \\
\hline \multirow[t]{3}{*}{$\mathrm{T} 3$} & Between Groups & .114 & 2 & .057 & .521 & .598 \\
\hline & Within Groups & 3.614 & 33 & .110 & & \\
\hline & Total & 3.728 & 35 & & & \\
\hline \multirow[t]{3}{*}{$\mathrm{T} 4$} & Between Groups & 3.611 & 2 & 1.805 & .211 & .811 \\
\hline & Within Groups & 281.938 & 33 & 8.544 & & \\
\hline & Total & 285.548 & 35 & & & \\
\hline \multirow[t]{3}{*}{$\mathrm{TSH}$} & Between Groups & 221.243 & 2 & 110.621 & .270 & .765 \\
\hline & Within Groups & 13517.661 & 33 & 409.626 & & \\
\hline & Total & 13738.904 & 35 & & & \\
\hline & & Sum of Squares & df & Mean Square & $\mathbf{F}$ & Sig. \\
\hline \multirow[t]{3}{*}{ pre_T3 } & Between Groups & 171.467 & 4 & 42.867 & .105 & .980 \\
\hline & Within Groups & 9372.702 & 23 & 407.509 & & \\
\hline & Total & 9544.169 & 27 & & & \\
\hline \multirow[t]{3}{*}{ pre_T4 } & Between Groups & 307.727 & 4 & 76.932 & 2.116 & .111 \\
\hline & Within Groups & 836.062 & 23 & 36.351 & & \\
\hline & Total & 1143.789 & 27 & & & \\
\hline \multirow[t]{3}{*}{ pre_TSH } & Between Groups & 13.986 & 4 & 3.497 & .237 & .915 \\
\hline & Within Groups & 339.797 & 23 & 14.774 & & \\
\hline & Total & 353.783 & 27 & & & \\
\hline
\end{tabular}




\section{Original Research Article}

Table 4 depicted the relationship between serum levels of T3, T4 and TSH values at the time of diagnosis of the disease in case of hypothyroidism and the upper lid retraction. In all cases $\mathrm{p}$ value is more than 0.05 so, it can be concluded that these hormone levels don't affect upper lid retraction.

Table 4: Comparison of serum levels of T3, T4 and TSH values at the time of diagnosis of the disease in case of hypothyroidism and the upper lid retraction.

\begin{tabular}{|l|l|c|c|c|c|c|}
\hline \multicolumn{2}{|l|}{} & Sum of Squares & df & Mean Square & F & Sig. \\
\hline pre_T3 & Between Groups & .325 & 2 & .162 & .061 & .941 \\
\hline & Within Groups & 77.525 & 29 & 2.673 & \\
\hline pre_T4 & Total & Between Groups & .207 & 31 & & \\
\hline & Within Groups & 348.096 & 29 & 12.003 & .009 & .991 \\
\hline & Total & 348.302 & 31 & & \\
\hline pre_TSH & Between Groups & 2126.377 & 2 & 1063.189 & .621 & .544 \\
\hline & Within Groups & 49622.444 & 29 & 1711.119 & & \\
\hline & Total & 51748.821 & 31 & & & \\
\hline
\end{tabular}

14 patients out of 72 patients which were studied had proptosis and out of which 9 patients belonged to hyperthyroid group and 5 had hypothyroid status.

Except serum levels of T4 (p value 0.024) in hyperthyroid group of patients at the time of diagnosis of the thyroid disease rest all subgroups of thyroid hormone levels were not significantly related with frequency or severity of the proptosis with the following $\mathrm{p}$ values as shown in Table 5 .

It also depicted the relationship between serum levels of T3, T4 and TSH values at the time of examination of the disease in case of hyperthyroidism and the proptosis. In all cases p value is more than 0.05 so, it can be concluded that these hormone levels don't affect proptosis.

The relationship between serum levels of T3, T4 and TSH values at the time of examination for this study in case of hypothyroidism and the proptosis is also depicted. In all cases p value is more than 0.05 so, it can be concluded that these hormone levels don't affect proptosis.

Table 5 also depicted the relationship between serum levels of T3, T4 and TSH values at the time of diagnosis of the disease in case of hyperthyroidism and proptosis. Serum level of T4 was found to be significantly related to the proptosis with p value of 0.024. In rest all cases $\mathrm{p}$ value is more than $0.05 \mathrm{so}$, it can be concluded that T3 and TSH hormone levels don't affect proptosis.

Table 5 also highlighted the relationship between serum levels of T3, T4 and TSH values at the time of diagnosis of the disease in case of hypothyroidism and the proptosis. In all cases $p$ value is more than 0.05 so, it can be concluded that these hormone levels don't affect proptosis.

Only 3 patients in the present study had chemosis and congestion all of which belonged to hyperthyroid status with no significant relationship with serum levels of thyroid hormone levels. P values of different subgroups of thyroid hormones are given in Table 6. It also depicted the relationship between serum levels of T3, T4 and TSH values at the time of examination of the disease in case of hyperthyroidism and the chemosis. In all cases $\mathrm{p}$ value is more than 0.05 So, it can be concluded that these hormone levels don't affect chemosis. Table 6 also depicted the relationship between serum levels of T3, T4 and TSH values at the time of diagnosis of the disease in case of hyperthyroidism and chemosis. In all cases p value is more than 0.05 so, it can be concluded that these hormone levels don't affect the chemosis. The relationship between serum levels of T3, T4 and TSH values at the time of examination of this study in case of hyperthyroidism and the congestion was also highlighted. In all cases $\mathrm{p}$ value is more than 0.05 so, it can be concluded that these hormone levels don't affect congestion. 
Original Research Article

Table 5: Relationship between serum levels of T3, T4 and TSH values at the time of examination and diagnosis of the disease in case of hyperthyroidism and hypothyroidism and the proptosis.

\begin{tabular}{|c|c|c|c|c|c|c|}
\hline \multirow{2}{*}{\begin{tabular}{|l|} 
\\
T3
\end{tabular}} & \multirow[b]{2}{*}{ Between Groups } & \multirow{2}{*}{$\begin{array}{c}\text { Sum of Squares } \\
6.217\end{array}$} & \multirow{2}{*}{$\frac{\text { df }}{2}$} & \multirow{2}{*}{$\begin{array}{c}\text { Mean Square } \\
3.109\end{array}$} & \multirow{2}{*}{$\begin{array}{c}\mathbf{F} \\
.717\end{array}$} & \multirow{2}{*}{$\begin{array}{l}\text { Sig. } \\
.496\end{array}$} \\
\hline & & & & & & \\
\hline & Within Groups & 130.101 & 30 & 4.337 & & \\
\hline & Total & 136.319 & 32 & & & \\
\hline \multirow[t]{3}{*}{$\mathrm{T} 4$} & Between Groups & 111.130 & 2 & 55.565 & 1.616 & .216 \\
\hline & Within Groups & 1031.754 & 30 & 34.392 & & \\
\hline & Total & 1142.884 & 32 & & & \\
\hline \multirow[t]{3}{*}{$\mathrm{TSH}$} & Between Groups & 72.091 & 2 & 36.046 & .972 & .390 \\
\hline & Within Groups & 1112.712 & 30 & 37.090 & & \\
\hline & Total & 1184.803 & 32 & & & \\
\hline & & Sum of Squares & df & Mean Square & $\mathbf{F}$ & Sig. \\
\hline \multirow[t]{3}{*}{ T3 } & Between Groups & .102 & 1 & .102 & .961 & .334 \\
\hline & Within Groups & 3.625 & 34 & .107 & & \\
\hline & Total & 3.728 & 35 & & & \\
\hline \multirow[t]{3}{*}{$\mathrm{T} 4$} & Between Groups & 2.998 & 1 & 2.998 & .361 & .552 \\
\hline & Within Groups & 282.551 & 34 & 8.310 & & \\
\hline & Total & 285.548 & 35 & & & \\
\hline \multirow[t]{3}{*}{$\mathrm{TSH}$} & Between Groups & 177.068 & 1 & 177.068 & .444 & .510 \\
\hline & Within Groups & 13561.836 & 34 & 398.878 & & \\
\hline & Total & 13738.904 & 35 & & & \\
\hline & & Sum of Squares & df & Mean Square & $\mathbf{F}$ & Sig. \\
\hline \multirow[t]{3}{*}{ pre_T3 } & Between Groups & 38.403 & 2 & 19.201 & .050 & .951 \\
\hline & Within Groups & 9505.766 & 25 & 380.231 & & \\
\hline & Total & 9544.169 & 27 & & & \\
\hline \multirow[t]{3}{*}{ pre_T4 } & Between Groups & 293.755 & 2 & 146.877 & 4.320 & .024 \\
\hline & Within Groups & 850.034 & 25 & 34.001 & & \\
\hline & Total & 1143.789 & 27 & & & \\
\hline \multirow[t]{3}{*}{ pre_TSH } & Between Groups & 7.329 & 2 & 3.664 & .264 & .770 \\
\hline & Within Groups & 346.455 & 25 & 13.858 & & \\
\hline & Total & 353.783 & 27 & & & \\
\hline & & Sum of Squares & df & Mean Square & $\mathbf{F}$ & Sig. \\
\hline \multirow[t]{3}{*}{ pre_T3 } & Between Groups & .676 & 1 & .676 & .263 & .612 \\
\hline & Within Groups & 77.174 & 30 & 2.572 & & \\
\hline & Total & 77.849 & 31 & & & \\
\hline \multirow[t]{3}{*}{ pre_T4 } & Between Groups & 13.034 & 1 & 13.034 & 1.166 & .289 \\
\hline & Within Groups & 335.268 & 30 & 11.176 & & \\
\hline & Total & 348.302 & 31 & & & \\
\hline \multirow[t]{3}{*}{ pre_TSH } & Between Groups & 2636.213 & 1 & 2636.213 & 1.610 & .214 \\
\hline & Within Groups & 49112.608 & 30 & 1637.087 & & \\
\hline & Total & 51748.821 & 31 & & & \\
\hline
\end{tabular}

The relationship between serum levels of T3, T4 and TSH values at the time of diagnosis of the disease in case of hyperthyroidism and the congestion was also presented. In all cases $p$ value is more than 0.05 so, it can be concluded that these hormone levels don't affect the congestion. 
Original Research Article

Table 6: Relationship between serum levels of T3, T4 and TSH values at the time of examination and diagnosis of the disease in case of hyperthyroidism and the chemosis along with congestion.

\begin{tabular}{|c|c|c|c|c|c|c|}
\hline & & Sum of Squares & df & Mean Square & $\mathbf{F}$ & Sig. \\
\hline \multirow[t]{3}{*}{$\mathrm{T} 3$} & Between Groups & 1.414 & 2 & .707 & .157 & .855 \\
\hline & Within Groups & 134.904 & 30 & 4.497 & & \\
\hline & Total & 136.319 & 32 & & & \\
\hline \multirow[t]{3}{*}{$\mathrm{T} 4$} & Between Groups & 114.811 & 2 & 57.405 & 1.675 & .204 \\
\hline & Within Groups & 1028.073 & 30 & 34.269 & & \\
\hline & Total & 1142.884 & 32 & & & \\
\hline \multirow[t]{3}{*}{$\mathrm{TSH}$} & Between Groups & 56.370 & 2 & 28.185 & .749 & .481 \\
\hline & Within Groups & 1128.433 & 30 & 37.614 & & \\
\hline & Total & 1184.803 & 32 & & & \\
\hline & & Sum of Squares & df & Mean Square & $\mathbf{F}$ & Sig. \\
\hline \multirow[t]{3}{*}{ pre_T3 } & Between Groups & 25.406 & 1 & 25.406 & .069 & .794 \\
\hline & Within Groups & 9518.763 & 26 & 366.106 & & \\
\hline & Total & 9544.169 & 27 & & & \\
\hline \multirow[t]{3}{*}{ pre_T4 } & Between Groups & 78.210 & 1 & 78.210 & 1.908 & .179 \\
\hline & Within Groups & 1065.579 & 26 & 40.984 & & \\
\hline & Total & 1143.789 & 27 & & & \\
\hline \multirow[t]{3}{*}{ pre_TSH } & Between Groups & .972 & 1 & .972 & .072 & .791 \\
\hline & Within Groups & 352.811 & 26 & 13.570 & & \\
\hline & Total & 353.783 & 27 & & & \\
\hline & & Sum of Squares & df & Mean Square & $\mathbf{F}$ & Sig. \\
\hline \multirow[t]{3}{*}{ T3 } & Between Groups & 1.414 & 2 & .707 & .157 & .855 \\
\hline & Within Groups & 134.904 & 30 & 4.497 & & \\
\hline & Total & 136.319 & 32 & & & \\
\hline \multirow[t]{3}{*}{$\mathrm{T} 4$} & Between Groups & 114.811 & 2 & 57.405 & 1.675 & .204 \\
\hline & Within Groups & 1028.073 & 30 & 34.269 & & \\
\hline & Total & 1142.884 & 32 & & & \\
\hline \multirow[t]{3}{*}{ TSH } & Between Groups & 56.370 & 2 & 28.185 & .749 & .481 \\
\hline & Within Groups & 1128.433 & 30 & 37.614 & & \\
\hline & Total & 1184.803 & 32 & & & \\
\hline & & Sum of Squares & df & Mean Square & $\mathbf{F}$ & Sig. \\
\hline \multirow[t]{3}{*}{ pre_T3 } & Between Groups & 25.406 & 1 & 25.406 & .069 & .794 \\
\hline & Within Groups & 9518.763 & 26 & 366.106 & & \\
\hline & Total & 9544.169 & 27 & & & \\
\hline \multirow[t]{3}{*}{ pre_T4 } & Between Groups & 78.210 & 1 & 78.210 & 1.908 & .179 \\
\hline & Within Groups & 1065.579 & 26 & 40.984 & & \\
\hline & Total & 1143.789 & 27 & & & \\
\hline \multirow[t]{3}{*}{ pre_TSH } & Between Groups & .972 & 1 & .972 & .072 & .791 \\
\hline & Within Groups & 352.811 & 26 & 13.570 & & \\
\hline & Total & 353.783 & 27 & & & \\
\hline
\end{tabular}

Intraocular pressure measured by applanation tonometry was not related to serum levels of thyroid hormones as tested by oneway Annova test. In all the subgroups the $\mathrm{p}$ value was more than 0.05 as given in Table 7 . It depicted the relationship between serum levels of T3, T4 and TSH values at the time of examination of the study in case of hyperthyroidism and the IOP. In all cases $\mathrm{p}$ value is more than 0.05 so, it can be concluded that these hormone levels don't affect IOP. The relationship between serum levels of T3, T4 and TSH values at the time of examination of this study in case of hypothyroidism and the IOP was also highlighted. In all cases p value is more than 0.05 so, it can be concluded that these hormone levels don't affect IOP. The relationship between serum levels of T3, T4 and TSH values at the time of diagnosis of the disease in case of hyperthyroidism 
Original Research Article

and IOP. In all cases p value is more than 0.05 so, it can be concluded that these hormone levels don't affect IOP. the relationship between serum levels of T3, T4 and TSH values at the time of diagnosis of the disease in case of hypothyroidism and the IOP. In all cases $\mathrm{p}$ value is more than $0.05 \mathrm{so}$, it can be concluded that these hormone levels don't affect the IOP.

Table 7: Serum levels of T3, T4 and TSH values at the time of examination and diagnosis of the study in case of hyperthyroidism and hypothyroidism and the IOP.

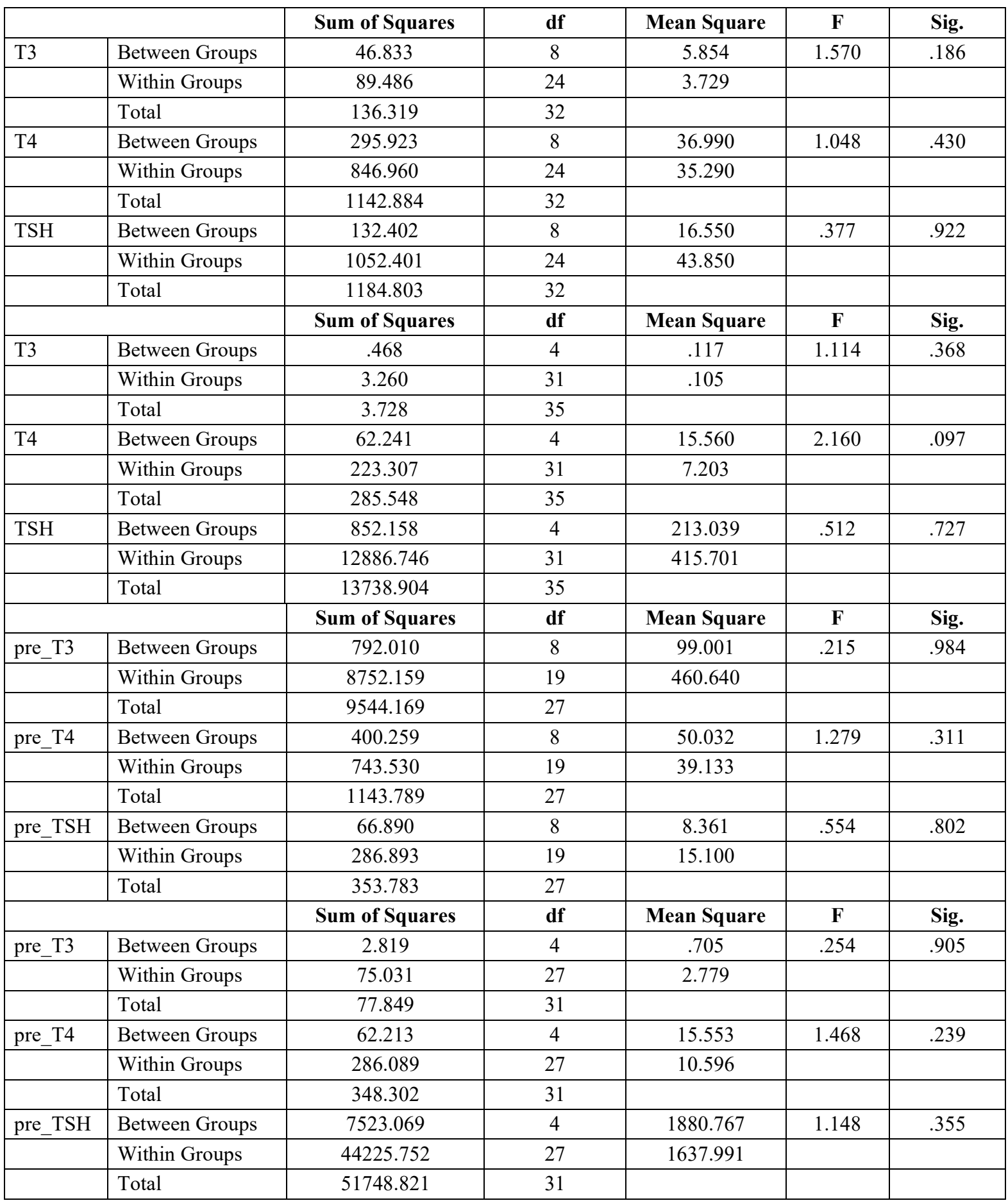

41 patients out of total of 72 patients had the dry eye disease as diagnosed with the help of a Schirmers test. 21 patients belonged to hyperthyroid group 18 patients belonged to hypothyroid group and rest 3 were having euthyroid status. Dry eye disease in thyroid patients was not found to be related with serum levels of T3, T4 and TSH (Table 8). It depicted the relationship between serum levels of T3, T4 and TSH values at the time of examination for the study in case of hyperthyroidism and the dry eye disease. In all cases p value is more than 0.05 so, it can be concluded that these hormone levels don't affect dry eye disease. 


\section{Original Research Article}

Table 8 also showed the relationship between serum levels of T3, T4 and TSH values at the time of examination of this study in case of hypothyroidism and the dry eye disease. In all cases $\mathrm{p}$ value is more than 0.05 so, it can be concluded that these hormone levels don't affect dry eye disease. The relationship between serum levels of T3, T4 and TSH values at the time of diagnosis of the disease in case of hyperthyroidism and the dry eye disease. In all cases p value is more than 0.05 so, it can be concluded that these hormone levels don't affect dry eye disease. The relationship between serum levels of T3, T4 and TSH values at the time of diagnosis of the disease in case of hypothyroidism and the dry eye disease. In all cases p value is more than 0.05 so, it can be concluded that these hormone levels don't affect dry eye disease.

Table 8: Serum levels of T3, T4 and TSH values at the time of examination and diagnosis of the study in case of hyperthyroidism and hypothyroidism and the dry eye disease.

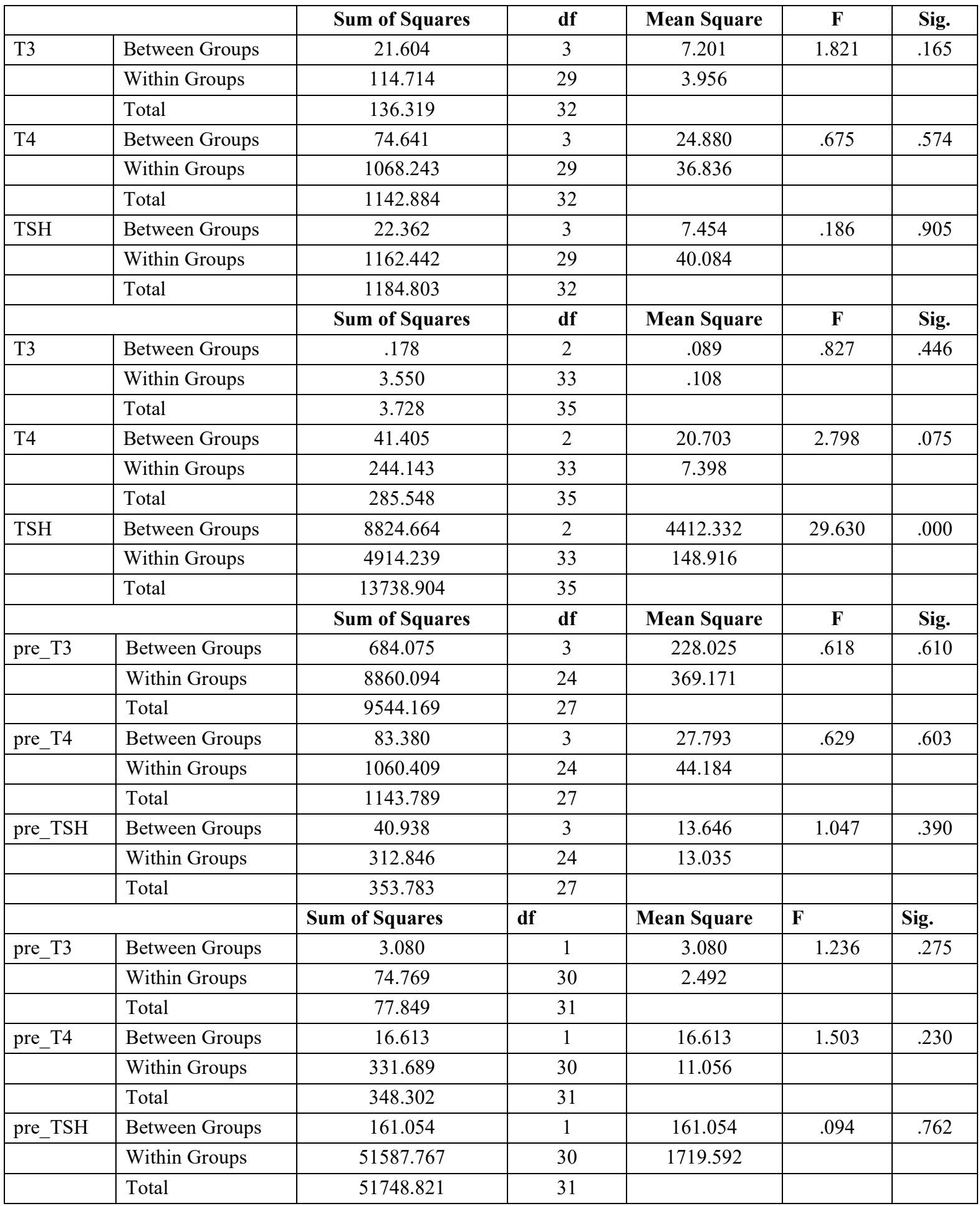


Original Research Article

Duration of thyroid disease was not found to be significantly related with the frequency and severity of any of the thyroid eye disease signs which were studied with the $\mathrm{p}$ value being more than 0.05 in each subgroup. Not a single patient in the present study had diplopia or strabismus. Three patients had limitation to extra ocular movement all of which belonged to hyperthyroid group. One patient in the present study with hyperthyroid status had undergone orbital decompression in both the eyes due to thyroid orbitopathy and her right eye was eviscerated due to endophthalmitis secondary to severe chronic exposure keratopathy, corneal perforation leading to evisceration of the right eye.

\section{Discussion}

The present study had 72 patients out of which 36 patients were hypothyroid, 34 were hyperthyroid and 2 were having euthyroid status. 54 out of 72 patients were females and 18 were males. Like in other studies, the present study also supports that thyroid eye disease is more commonly seen in women than in men $[2,7]$.

Most common age group affected in the current study is 4150 years. As per the available literature thyroid eye disease has the bimodal peak incidence in $5^{\text {th }}$ and sixth decade in both men and women this is also proven in the current study [7]. In a study carried out in Accra the mean age group affected was 45.22 years in the current study it is 43.07 years while in a study carried out at Nepal it was 42.39 years $[13,14]$.

The most common thyroid eye disease was found to be dry eye (41 patients) followed by upper lid retraction (19 patients) and proptosis (14 patients) in the current study. Upper eyelid retraction being the second most frequent sign here in the current study is the most frequent sign of TED in other studies/literature found [11,12]. Upper lid retraction is more common in hyperthyroid cases followed by hypothyroid and Euthyroid cases which is also seen in the current study [8].

Serum level of T3 at the time of study was found to be significantly correlated with the severity and the frequency of upper lid retraction with the $\mathrm{p}$ value of 0.009 . Serum levels of T4 at the time of diagnosis of hyperthyroid was found to be significantly related with the severity and the frequency of the proptosis with the $\mathrm{p}$ value of 0.024 .

Rest all signs of thyroid eye disease (Chemosis, congestion, dry eye) and intraocular pressure were found to be not associated or related with serum levels of T3, T4 and TSH at the time of examination or at the time of diagnosis.

Duration of thyroid disease was not found to be significantly related with the frequency and severity of any of the thyroid eye disease signs which were studied with the $\mathrm{p}$ value being more than 0.05 in each subgroup.

However, there are no studies or literature found on association of serum levels of thyroid hormones with thyroid eye disease so the results of the present study couldn't be compared with any other similar study.

\section{Limitations of the present study}

1. Limited sample size: Due to the limited duration and unavailability of the records of thyroid profile at the time of diagnosis the sample size is less but this study serves as the pilot study for the future study with a bigger sample size.

2. This study doesn't include the management of the patients for their thyroid disease so the effect of it on the manifestations of thyroid eye disease couldn't be studied

\section{Conclusion}

1. Out of 72 cases which were studied, 36 patients were found to be of hypothyroid status, 34 patients were having hyperthyroidism and 2 patients had euthyroid status.

2. Females were seen to be more commonly affected than men (54 VS 18)

3. Most common age group affected with TED was 41-50 years with the mean age of 43.07

4. The most common thyroid eye disease was found to be dry eye (41 patients) followed by upper lid retraction (19 patients) and proptosis (14 patients).

5. Serum level of T3 at the time of study was found to be significantly correlated with the severity and the frequency of upper lid retraction.

6. Serum levels of T4 at the time of diagnosis of hyperthyroid was found to be significantly related with the severity and the frequency of the proptosis.

7. Rest all signs of thyroid eye disease (Chemosis, congestion, dry eye) and intraocular pressure were found to be not associated or related with serum levels of T3, T4 and TSH at the time of examination or at the time of diagnosis.

8. Duration of thyroid disease was not found to be significantly related with the frequency and severity of any of the thyroid eye disease signs which were studied with the $p$ value being more than 0.05 in each subgroup.

9. One patient in the present study with hyperthyroid status had undergone orbital decompression in both the eyes due to thyroid orbitopathy and her right eye was eviscerated due to endophthalmitis secondary to severe chronic exposure keratopathy, corneal perforation leading to evisceration of the right eye. So, from this observation, it can be concluded that TED can be sight threatening, disfiguring and needs the prompt appropriate treatment 


\section{Original Research Article}

\section{What the study adds to the existing knowledge?}

This kind of study has never been done and this study helps to find the relationship between serum levels of T3,T4 and TSH at the time of diagnosis of thyroid disease and at the time of current examination for the study also the duration of the thyroid disease with thyroid eye disease manifestation. Which in turn can give us idea about managing the particular hormonal levels which are significantly related to the manifestation of particular thyroid eye disease type. So, there is further scope to carry out a new study which will study the management of the serum levels of these thyroid hormones with different modes of treatment and thyroid eye disease.

\section{Author's contribution}

Dr. Priyanka Choudhari: Conduct of study

Dr. Ugam Usgaonkar: Guidance.

Dr. Dipti Shrivastav: Guidance.

Funding: No funding sources

Conflict of interest: None declared

Ethical Approval: This study was approved by the Institutional Ethics Committee

\section{References}

1. Colm McAlinden. An overview of thyroid eye disease. Eye Vis (Lond).2014; 1:9.doi: 10.1186/s40662-014-0009-8

2. Lazarus JH. Epidemiology of Graves orbitopathy and relationship with thyroid disease. Best Pract Res Clin Endocrinol Metab. 2012; 26 (3): 273-279. doi: 10.1016/j. beem. 2011. 10.005.

3. Perros P, Crombie AL, Matthews JN, Kendall-Taylor P. Age and gender influence the severity of thyroid-associated ophthalmopathy: a study of 101 patients attending a combined thyroid-eye clinic. Clinic Endocrinol. 1993; 38 (4): 367-372. doi: https://doi.org/10.1111/j.1365-2265. 1993. tb00516.x.

4. Kanskis clinical ophthalmology, A systematic approach, 8th edition 2016.

5. Albert Jacobiecs. Volume 3. 3rd Edition 2008. Chapter 229, Pathophysiology of Graves Orbitopathy, 2913-2926.
6. Perros P, Dickinson AJ, Kendall-Taylor P. Clinical presentation and natural history of Graves' ophthalmopathy. InThyroid Eye Disease 2001 (pp. 119-136). Springer, Boston, MA. doi: https://doi.org/ 10. 1007/978-14615-1447-3_8.

7. Vijayleela M, Babu B. Ophthalmic manifestations in thyroid disease. IOSR J Dent Med Sci. 2017;16(1):59-65. doi: 10.9790/0853-1601045965.

8. Raja Maheshwari, Ezkiel Weis. Thyroid associated orbitopathy. Indian J Ophthalmol. 2012;60(2):87-93. doi: 10.4103/0301-4738.94048.

9. Garrity JA, Bahn RS. Pathogenesis of Graves ophthalmolopathy: Implications for prediction, prevention and treatment. Am J Ophthalmol 2006:142(1):146-153. doi: https://doi.org/10.1016/j.ajo.2006.02.047.

10. Lehman GM, Garcia-Bates TM, Smith TJ, Feldon SE, Phipps RP. Regulation of lymphocyte function by PPARgamma: Relevance to thyroid eye disease-related inflammation. PPAR Res 2008; 2008:895901. doi: 10.1155/ 2008/895901.

11. Bartley GB, Fatourechi V, Kadrmas EF, Jacobsen SJ, Ilstrup DM, Garrity JA, et al. Clinical features of Graves ophthalmopathy in an incidence cohort. Am J Ophthalmol. 1996; 121(3):284-290. doi: https://doi.org/10.1016/S00029394 (14)70276-4.

12. Saks ND, Burnstine MA, Putterman AM. Glabellar rhytids in thyroid associated orbitopathy. Ophthal Plast Recontsr Surg. 2001;17(2):91-95.

13. Ackuaku Dogbe EM, Akpalu J, Abaidoo B. Epidemiology and clinical features of thyroid associated orbitopathy in ACCRA. Middle East Afr J Ophthalmol. 2017;24(4):183-189. doi: 10.4103/meajo.MEAJO_91_17.

14. Lavaju P, Badhu BP, Maskey R. Pattern of ocular manifestations in patients with thyroid disease presenting in Eastern Nepal. Thyroid Res Prac. 2019;16(1):20-25. doi: 10.4103/trp.trp_38_18.

15. Sabita P, Ajit T, Narayan SD, Kumar SA, Niranjan A. Ocular manifestations in thyroid eye disorder: a crosssectional study from Nepal. Int J Clin Med. 2016;7(12):814823. doi: $10.4236 / \mathrm{ijcm} .2016 .712088$.

\section{How to cite this article?}

Choudhari P.C, Usgaonkar U, Shrivastav D. Ophthalmic manifestations of thyroid disease and the association of serum levels of T3, T4 and TSH with thyroid eye disease. Trop J Ophthalmol Otolaryngol.2019;4(8):468-477.doi:10.17511/jooo.2019.i08.04 